Vol. 8 (3): 629-636 (2018)

\title{
ECOLOGICAL-GEOBOTANIC MAPPING (SOME ASPECTS OF METHODOLOGY AND METHODS APPROACHES IN VEGETATION (MAPPING)
}

\author{
Alexander Sizykh ${ }^{1 *}$, Alexey Shekhovtsov ${ }^{2}$ \\ ${ }^{1 *}$ Siberian Institute of Plant Physiology and Biochemistry, Siberian Branch of Russian Academy of Sciences, \\ 665033, Irkutsk, Lermontova str., 132, Box 317, Russia; \\ ${ }^{2}$ Sochava Institute of Geography, Siberian Branch of Russian Academy of Sciences, 664033,Irkutsk, Ulan- \\ Batorskaya str., 1, Russia;
}

"Corresponding author: Alexander Sizykh, e-mail: alexander.sizykh@gmail.com;

Received May, 2018; Accepted May, 2018; Published June, 2018;

DOI: https://doi.org/10.31407/ijees8325

UOI license: http://u-o-i.org/1.01/ijees/23565781

\begin{abstract}
Cartographic studies of vegetation determines a choice of the principles of its classification, and this is just the essence of the performed studies. The choice of phytocoenoses classification depends on the aim of the performed cartographic studies. Let us make an emphasis on main conditions and statements of geobotanic mapping of different scales and branch-wise purposes. We use a study method combination of geobotanical survey with largescale schematic mapping and vegetation mapping on the base of field deciphering of aerospace picture made in different years together with phytocoenoses monitoring during different seasons and years forming at the interface of zonal forests and extrazonal steppe.
\end{abstract}

Key words: ecological-geobotanic mapping, ecotones, communities of forests and extrazonal steppe contact, zonal vegetation, Pre-Baikal areas 